\title{
Reconstruction of temporal variations of evapotranspiration using instantaneous estimates at the time of satellite overpass
}

\author{
E. Delogu ${ }^{1}$, G. Boulet ${ }^{1}$, A. Olioso ${ }^{2,3}$, B. Coudert ${ }^{1}$, J. Chirouze ${ }^{1}$, E. Ceschia ${ }^{1}$, V. Le Dantec ${ }^{1}$, O. Marloie ${ }^{2,3}$, \\ G. Chehbouni ${ }^{1}$, and J.-P. Lagouarde ${ }^{4}$ \\ ${ }^{1}$ Centre d'études spatiales de la biosphère, CESBIO - UMR5126, UPS, CNRS, CNES, IRD, Toulouse, France \\ ${ }^{2}$ INRA, EMMAH - UMR1114, 84914 Avignon, France \\ ${ }^{3}$ UAPV, EMMAH - UMR1114, 84000 Avignon, France \\ ${ }^{4}$ EPHYSE INRA, Bordeaux, France
}

Correspondence to: E. Delogu (emilie.delogu@cesbio.cnes.fr)

Received: 12 January 2012 - Published in Hydrol. Earth Syst. Sci. Discuss.: 6 February 2012

Revised: 26 June 2012 - Accepted: 24 July 2012 - Published: 27 August 2012

\begin{abstract}
Evapotranspiration estimates can be derived from remote sensing data and ancillary, mostly meterorological, information. For this purpose, two types of methods are classically used: the first type estimates a potential evapotranspiration rate from vegetation indices, and adjusts this rate according to water availability derived from either a surface temperature index or a first guess obtained from a rough estimate of the water budget, while the second family of methods relies on the link between the surface temperature and the latent heat flux through the surface energy budget. The latter provides an instantaneous estimate at the time of satellite overpass. In order to compute daily evapotranspiration, one needs an extrapolation algorithm. Since no image is acquired during cloudy conditions, these methods can only be applied during clear sky days. In order to derive seasonal evapotranspiration, one needs an interpolation method. Two combined interpolation/extrapolation methods based on the self preservation of evaporative fraction and the stress factor are compared to reconstruct seasonal evapotranspiration from instantaneous measurements acquired in clear sky conditions. Those measurements are taken from instantaneous latent heat flux from 11 datasets in Southern France and Morocco. Results show that both methods have comparable performances with a clear advantage for the evaporative fraction for datasets with several water stress events. Both interpolation algorithms tend to underestimate evapotranspiration due to the energy limiting conditions that prevail during cloudy days. Taking into account the diurnal variations of the evaporative fraction according to an empirical relationship derived
\end{abstract}

from a previous study improved the performance of the extrapolation algorithm and therefore the retrieval of the seasonal evapotranspiration for all but one datasets.

\section{Introduction}

Evaporation is the largest water loss component of continental surfaces. In semi-arid areas, more than $80 \%$ of the annual available water is lost through evapotranspiration. In most countries, the largest water user is the irrigated agriculture, which represents more than $80 \%$ of all uses, with a low efficiency no greater than $50 \%$ in many cases (PNUE PAM Plan Bleu, 2004). For countries facing water shortage, or likely to suffer from more frequent drought spells under climate change scenarios, there is a great need to rationalize this use, and therefore to monitor more closely the water resources. Amongst the fluxes that the different actors of the water sector need to assess, evapotranspiration is of major importance. It is also important in the wider context of hydrological prediction and monitoring.

Although the water budget can be fairly easily monitored by the farmer-at-plot scale, it is much more difficult for regional authorities or national planners to monitor water allocation and use at the relevant scales, i.e. the perimeter and the basin scales. To do so, remote sensing (RS) data is increasingly used because it allows for the description of the surface with a temporal scale lower than a few weeks. This is 
particularly important to follow the growth of vegetation at most scales ranging from plot to region.

Many methods exist to compute evapotranspiration with the help of RS data (Courault et al., 2005; Kalma et al., 2008). Some of them rely only on the atmospheric demand through different radiation and atmospheric variables derived from remote sensing (Venturini et al., 2008). Since evapotranspiration largely depends on the availability of water, which is often greater in the root zone than at the soil surface, surface losses depend on the intensity of transpiration. Many methods, especially those designed for irrigated agriculture, which is usually not short of water, compute a potential or reference evapotranspiration rate and weigh the latent heat flux by an estimated amount of vegetation present for each pixel through the use of a vegetation index such as the Normalized Difference Vegetation Index (NDVI) (Cleugh et al., 2007). But this does not help when vegetation suffers from water stress, which means that these methods have little applicability in natural lands, for rainfed agriculture areas or for deficit irrigation systems, which are more sensitive to climate fluctuations and drought.

Since evaporation is the most efficient way to dissipate extra energy at the surface, there is a tight coupling between water availability and surface temperature under water stress conditions. Therefore, information in the thermal infrared (TIR) domain is the most appropriate way to assess actual evaporation and soil moisture status at relevant space and time scales (Boulet et al., 2007; Hain et al., 2009). Methods to estimate evapotranspiration from satellite data in the TIR domain are reviewed in Kalma et al. (2008) and Kustas and Anderson (2009).

Geostationary satellite provides information in the TIR domain with a frequency down to $15 \mathrm{~min}$, but for resolutions well above the kilometric scale (Anderson et al., 2011). On the other hand, some sun synchronous satellites (MODIS, AATSR) provide data once or twice a day at kilometric resolution. For shorter spatial scales, of the same order of magnitude as the average field size in most agricultural systems, data can be available every week or so if data from several platforms (e.g. ASTER, Landsat, among others) are combined. The large temporal gaps between two successive acquisitions with the existing satellites lead to the proposal of the MISTIGRI (MIcro Satellite for Thermal Infrared GRound surface Imaging, Lagouarde et al., 2012) satellite mission by CNES (Centre National d'Etudes Spatiales, French space agency) and the scientific community. This mission would provide surface temperature data with a daily revisit and a 50 to $60 \mathrm{~m}$ spatial resolution and would therefore be particularly suited to monitoring evapotranspiration at field scale.

Most methods using information in the TIR domain rely on data acquired once-a-day, generally around noon, in late morning or early afternoon. As a consequence, the diurnal cycle of the energy budget is not accounted for and most methods compute an instantaneous energy budget at the time of the satellite overpass. They thus provide a single instantaneous evaporation or latent heat flux, whereas a daily average is usually required for hydrological applications.

In order to estimate daily and seasonal evapotranspiration (ET) using remote sensing, there is a need to extrapolate daily ET from an instantaneous measurement to reconstruct hourly variations of ET and interpolate ET between two successive daily ET values to reconstruct continuous sequences of daily cumulated ET. Cloud occurrence is also an issue and no data is acquired under cloudy conditions. Data availability therefore depends on both the overpass frequency and the cloud cover conditions.

Different methods have been developed to scale daily evapotranspiration from a one-time-of-day measurement. These methods essentially rely on a self preservation or a known diurnal shape of the ratio of the latent heat flux (LE) to a scale factor whose diurnal evolution can in turn be easily resolved. This scale factor is usually either a radiation term (global solar incoming radiation $R_{\mathrm{g}}$, net radiation $R_{\mathrm{n}}$, total incoming radiation, etc.), the available energy $\left(R_{\mathrm{n}}-G\right.$ where $G$ is the ground heat flux) or a maximum evapotranspiration rate, either a potential evapotranspiration rate or the reference evapotranspiration rate defined by Allen et al. (1998).

The most commonly used method assumes the diurnal self-preservation of the evaporative fraction (EF). The evaporative fraction is defined as the ratio between the latent heat flux and the available energy at the land surface $\left(\mathrm{EF}=\mathrm{LE} /\left(R_{\mathrm{n}}-G\right)\right)$.

Shuttleworth et al. (1989), Nichols and Cuenca (1993) and Crago and Brutsaert (1996) observed from in situ measurements taken on a few typical days and in various bio-pedoclimatic conditions that $\mathrm{EF}$ is nearly constant during daytime under clear sky days.

Gentine et al. (2007) investigated the diurnal behavior of $\mathrm{EF}$ and its environmental dependencies in details using a Soil-Vegetation-Atmosphere Transfer model applied to a wheat crop in a semi-arid climate. The study showed that $\mathrm{EF}$ is almost independent of solar radiation and wind speed, but strongly depends on soil moisture availability and canopy fraction cover. Daytime self-preservation of EF is not always satisfied when fractional vegetation cover is close to $100 \%$. Indeed, for a fully vegetated surface, EF shows a pronounced rise in the afternoon due to the inversion of sensible heat flux. This effect is stronger with high soil moisture, when EF values exceed unity, and with increasing LAI (leaf area index). Gentine et al. (2007) underlined also that the daytime self-preservation of EF can be revised in order to obtain a concave-up shape of EF more representative of typical diurnal fluctuations. This shape is obtained analytically from a sinusoidal solar radiation forcing by Gentine et al. (2011).

Hoedjes et al. (2008) also revised the assumption of EF daytime self preservation in order to obtain a better estimate of evapotranspiration. They parameterized EF diurnal shape as a function of relative humidity and incoming solar 
radiation. The study showed that EF remains fairly constant during daytime under dry conditions and follows a concaveup shape under wet conditions. This work also underlined that using a constant EF value throughout daytime induces significant errors when calculating daily ET.

Other methods using different parameters than EF have also been tested in the past. For instance, Allen et al. (2007) provided an interpretation of the pronounced rise of $\mathrm{EF}$ in the afternoon. These authors show that the assumption of constant EF during the day can underpredict $24 \mathrm{~h}$ ET in arid climates where afternoon advection or increased afternoon wind speed may increase ET in proportion to $R_{\mathrm{n}}-G$. They stated that the diurnal self preservation of the stress factor (the ratio of the evaporation rates in actual and potential conditions) during a day appears to be generally valid for agricultural crops that have been developed to maximize photosynthesis and thus stomatal conductance. This ratio may decrease during the afternoon for some native vegetation under water shortage conditions, where plants endeavor to conserve soil water. Under these conditions, the $24 \mathrm{~h}$ stress factor must be modeled as some fraction of instantaneous stress factor. This requires local study and measurement to develop the needed functions.

Chavez et al. (2008) and Colaizzi et al. (2006) selected and tested several ET extrapolation methods (including those based on EF and the stress factor mentioned previously) to estimate daily ET.

In particular, Chavez et al. (2008) used data on soybean and corn over one summer month. They showed that estimation errors for all methods and both crops vary from $-5.7 \%$ $( \pm 4.8)$ to $26.0 \%$ ( \pm 15.8$)$. Extrapolated values based on the EF method were closer to observed ET values measured by an eddy covariance system. This method reported an average underestimation error of $-0.3 \mathrm{~mm} \mathrm{day}^{-1}$ for corn. A solar radiation-based ET extrapolation method performed relatively well with an estimation error on daily ET of $2.2 \%$ $( \pm 10.1)$ for both crops. An alfalfa reference ET-based extrapolation fraction method yielded an overall daily ET overestimation of about $4.0 \%,( \pm 10.0)$ for both crops.

The results of Colaizzi et al. (2006) also showed that the methods were more efficient when used around noon (12:45 UTC in the study). Each of the five methods tested performed better at this time of the day (average RMSE - root mean squared error - of $0.57 \mathrm{~mm} \mathrm{day}^{-1}$ ). Crops involved in this study were fully irrigated alfalfa (irrigated to meet the full ET requirement; 304 days), dryland grain sorghum (124 days), partially irrigated cotton (irrigated to meet $50 \%$ of the full ET requirement; 59 days), and bare soil after tilling following a grain sorghum crop (66 days). The climate for this dataset was semi-arid. According to their conclusions, scaling with the help of a model based on the grass reference ET is the recommended basis to reconstruct daily ET, but for surfaces having low ET, using a model based on the evaporative fraction may give slightly better estimates, with RMSE values of $0.47 \mathrm{~mm} \mathrm{day}^{-1}$ (mean observed ET:
$1.4 \mathrm{~mm} \mathrm{day}^{-1}$ ) for bare soil, $0.47 \mathrm{~mm} \mathrm{day}^{-1}$ (mean observed ET: $3.9 \mathrm{~mm} \mathrm{day}^{-1}$ ) for cotton, and $0.50 \mathrm{~mm} \mathrm{day}^{-1}$ (mean observed ET: $4.1 \mathrm{~mm} \mathrm{day}^{-1}$ ) for sorghum.

Except for the study by Colaizzi et al. (2006), the different works presented above were generally based on a small range of bio-pedo-climatic conditions and the methods were tested for relatively short time periods. Indeed, the periods of study were often limited to a few days only, and rarely exceeded a few weeks. In some studies, results were obtained for particular and typical situations (e.g. stressed, rainy, dry, moist, full cover, bare soil), but mostly for isolated days picked from seasonal data sets. Moreover, most studies did not contest the assumption of the self-preservation of the scale factor during the day.

Since the main goal of daily and seasonal ET reconstruction is to estimate daily ET from satellite data operationally (and therefore routinely), it is difficult to implement methods based on biophysical characteristics that are temporally and spatially difficult to infer, such as soil moisture or water stress. For instance, it is not easy to implement a different EF diurnal shape for stressed and unstressed periods, as proposed by Hoedjes et al. (2008). There is moreover no consensus on the general trend of EF diurnal fluctuations, which can exhibit for a given location either a "flat", "tangent-like" or a "concave-up" shape (Van Niel et al., 2011). Thus, the aim for operational considerations is to estimate the error associated with the "self preservation" hypothesis, which is well suited (and up to now largely used) to reconstruct daily and seasonal ET from instantaneous estimates of ET from satellite data, and then test the impact of using one common shape for the scale factor for all sites and all times on the daily ET reconstruction.

One must note that unlike the evaporative fraction, and as reported by Allen et al. (2007), there is no documentation, and a fortiori no consensus, on the most common shape of the stress factor during the day. The self preservation is, to our knowledge, the only tested hypothesis for daily ET reconstruction using methods based on a potential or a reference evapotranspiration rate.

Within that context, the objectives of this paper are twofold:

1. To assess the performance of two methods classically used to reconstruct daily (extrapolation) and seasonal (interpolation) ET from sparse instantaneous estimates, as a function of revisit and time of acquisition.

2. To check for a possible improvement of the method that performs best.

Within these two main objectives, the interests of the study rely on testing classical methods on a large range of multisite data and to reconstruct ET at daily and seasonal scale. In order to take into account the operational constraints imposed by the existing or future satellite platforms (e.g. overpass time, revisit), the hypothesis concerning the time and the 
frequency at which the instantaneous estimates are collected in order to reconstruct ET is also discussed.

\section{Background theory}

In this section, we present the background theory for the two methods tested in this study: the evaporative fraction (EF) method and the stress factor (SF) method. Both methods are classically used to reconstruct daily and seasonal ET from an instantaneous estimate. The rationale for the estimation of the scaling factor for the evaporative fraction (i.e. available energy) and the stress factor (i.e. potential evapotranspiration) are also described and their relative advantages or drawbacks for operational applications are analyzed.

\subsection{Evaporative Fraction (EF) method}

The first method is based on the use of the evaporative fraction. The evaporative fraction is defined as the ratio between the instantaneous latent heat flux (LE) and the instantaneous available energy at the land surface $\left(R_{\mathrm{n}}-G\right) . R_{\mathrm{n}}$ is the net radiation; $G$ is the soil heat flux (i.e. $\mathrm{EF}=\mathrm{LE} /\left(R_{\mathrm{n}}-G\right)$ ).

In this method, we assume that EF is constant during daytime. The daily cumulative evapotranspiration $\left(\mathrm{ET}_{\mathrm{d}}\right)$ can thus be expressed as the product of the daily cumulative available energy $\left(\mathrm{AE}_{\mathrm{d}}\right)$ and the instantaneous estimate of $\mathrm{EF}$ at the time of satellite overpass:

$\mathrm{ET}_{\mathrm{d}}=\mathrm{EF} \cdot \mathrm{AE}_{\mathrm{d}}$

Instantaneous estimates of $R_{\mathrm{n}}$ and $G$ are determined with relatively good precision from remote sensing data alone, without the need of any additional in situ data. This method is therefore particularly suited for mapping daily or seasonal evapotranspiration at large scale. $R_{\mathrm{n}}$ is given by

$R_{\mathrm{n}}=(1-\alpha) \cdot R_{\mathrm{g}}+\varepsilon \cdot R_{\mathrm{atm}}-\varepsilon \cdot \sigma \cdot T_{\mathrm{s}}^{4}$,

where $R_{\mathrm{g}}$ is the global radiation, $\alpha$ the albedo, $\varepsilon$ the surface emissivity, $R_{\mathrm{atm}}$ the atmospheric longwave radiation, $\sigma$ the Stefan-Boltzman constant and $T_{\mathrm{S}}$ the surface temperature. Also, several empirical functions based on surface temperature and/or NDVI exist to compute the ratio between $G$ and $R_{\mathrm{n}}$ (see examples in papers describing the most widely used single source energy balance models, e.g. Bastiaanssen et al., 1998; Santanello and Friedl, 2003; Su, 2002). These functions may require to be calibrated for each specific site (Kpemlie, 2009).

The EF method requires the diurnal course of available energy (AE), which is not routinely available from meteorological stations or satellite products. Various formulations have been proposed for estimating daily $\mathrm{AE}$ from an instantaneous estimate at a given time of the day (see Chavez et al., 2008). Sobrino et al. (2007) used parametric equations to derive daily net radiation from instantaneous net radiation as a function of the day in the year and the acquisition time of satellite data (surface temperature and albedo).

Hoedjes et al. (2008) used a parameterization of AE based on a function of global incoming radiation $\left(R_{\mathrm{g}}\right)$ and atmospheric thermal irradiance $\left(R_{\mathrm{atm}}\right)$. In their study, the proposed parameterization showed RMSE as low as $30 \mathrm{~W} \mathrm{~m}^{-2}$ between simulated and observed $\mathrm{AE}$ for an olive orchard in semi-arid climate.

Since the diurnal variations of $R_{\text {atm }}$ are relatively small compared to $R_{\mathrm{g}}$, the parameterization used here is a variation of the Jackson et al. (1983) algorithm, based on the assumption that ET and AE have the same diurnal course as the incoming global solar radiation $R_{\mathrm{g}}$ (Fig. 2).

$\mathrm{AE}_{\mathrm{d}}=R_{\mathrm{g}_{\mathrm{d}}} \cdot \frac{\mathrm{AE}_{t}}{R_{\mathrm{g}_{t}}}$

where $A E_{d}$ is the daily available energy and $R_{g_{d}}$ the daily global incoming solar radiation. $\mathrm{AE}$ and $R_{\mathrm{g}}$ are measurements of these components at the time of the satellite overpass.

A mean fixed value (observation average) of $R_{\mathrm{g}}$ is imposed at night to avoid a bias for nocturnal values.

According to Hoedjes et al. (2008), EF self-preservation is a valid assumption under dry conditions but no longer under wet conditions. In the latter conditions, EF shows a concaveup shape. In agreement with the results reported by Lhomme and Elguero (1999), Gentine et al. (2007) and Hoedjes et al. (2008) have shown that assuming a constant EF underestimates actual EF and therefore ET.

According to Gentine et al. (2007), the diurnal shape of EF depends on both atmospheric forcing and surface conditions. Hoedjes et al. (2008) introduced an empirical parameterization of the EF diurnal cycle:

$\mathrm{EF}=\left[1.2-\left(0.4 \cdot \frac{R_{\mathrm{g}}}{1000}+0.5 \cdot \frac{\mathrm{RH}}{100}\right)\right] \cdot\left(\frac{\mathrm{EF}_{12 \mathrm{obs}}}{\mathrm{EF}_{12 \mathrm{sim}}}\right)$,

where $\mathrm{EF}_{12 \mathrm{obs}}$ is the observed values at noon, $\mathrm{EF}_{12 \mathrm{sim}}$ is calculated at noon with the first part of the equation and $\mathrm{RH}$ is the relative humidity.

Hoedjes et al. (2008) tested the parameterization for an olive tree orchard in Morocco over a ten-day wet period for daytime values only and showed that the errors on ET calculations are reduced to less than $0.5 \%$, whereas an underestimation of $8 \%$ on average was observed when assuming EF self preservation. The validity of this empirical formulation for other plant types and climates is questionable.

\subsection{Stress Factor (SF) method}

A second well known method, called SF method, is presented below. While the EF method is based on scaling evapotranspiration with the help of available energy, the SF method scales ET with the potential evapotranspiration. The 
functional equivalent of the evaporative fraction (the non dimensional product factor) is thus the stress factor SF:

$\mathrm{ET}_{\mathrm{d}}=\mathrm{SF} \cdot \mathrm{ETP}_{\mathrm{d}}$

where the stress factor SF is computed as the ratio of the instantaneous evapotranspiration rate (ET) and the instantaneous potential evapotranspiration (ETP), both estimated at the time of the satellite overpass $(\mathrm{SF}=\mathrm{ET} / \mathrm{ETP}) . \mathrm{ETP}_{\mathrm{d}}$ is the daily potential evapotranspiration. $\mathrm{ET}_{\mathrm{d}}$ is the daily actual evapotranspiration.

ETP is usually derived from a surface energy balance model (Lhomme, 1997) or a reference calculation such as the FAO-56 (Food and Agriculture Irrigation and Drainage Paper No. 56) method for grass reference (Allen et al., 1998) or the ASCE (American Society of Civil Engineers) PenmanMonteith equation for alfalfa reference (Allen et al., 2007).

Again, the diurnal course of the stress factor (SF) is neglected, which is consistent with the previous studies. Furthermore, no prior shape of this ratio has been described in the literature.

The drawback of the SF method is that it uses more input data than the EF method (Table 1). Furthermore, all inputs used for EF method can be derived from remote sensing while inputs for the SF method have to be computed from a model of ETP. The robustness of the ETP model will be tested in Sect. 4.1.2.

In this paper, we do not test a method based on reference evapotranspiration. Instead, we use an extension of the combination equation which computes ETP as the maximum evaporation of a given surface by taking into account its real vegetation extent, unlike the reference evapotranspiration, which is valid only for a reference cover. Moreover, this equation requires the same amount of inputs as the reference evapotranspiration model except for information on the true vegetation cover (through LAI or NDVI products), which is easily derived from remote sensing.

The energy balance model used to compute ETP and ETP $\mathrm{d}_{\mathrm{d}}$ has been described in Gentine et al. (2007). It is a dual-source energy budget model which requires various input data related to the atmosphere, such as air temperature, wind speed, relative humidity and global radiation, as well as vegetation development and physiology data, such as LAI, vegetation height, minimum stomatal resistance, and soil type(s). Some of these data can be taken from nearby meteorological stations and from remote-sensing data. But others, like the minimum surface resistance to transpiration, as well as the various parameters of the aerodynamic resistances, are more difficult to infer without a proper in situ measurement. ETP is computed by specifying minimum values for the stomatal closure due to water stress and zero-value for the soil resistance to evaporation representing the extraction of water from the top soil porous medium. Default values typical for herbaceous vegetation are assigned to the plant parameters ( 0.2 for albedo, $100 \mathrm{~s} \mathrm{~m}^{-1}$ for the minimum stomatal resistance per LAI, $0.8 \mathrm{~m}$ for the maximum vegetation height).
Table 1. Inputs data used for the two methods and in the SVAT Model.

\begin{tabular}{|c|c|c|c|c|}
\hline & Input data & Derived from & & \\
\hline \multirow[t]{4}{*}{ EF method } & LE & & SS & \\
\hline & $\mathrm{Rn}$ & & SS & \\
\hline & G & & S & \\
\hline & $\mathrm{Rg}$ & Met. Station or RS & & \\
\hline \multirow[t]{3}{*}{ SF method } & LE & & QS & \\
\hline & ETP & SVAT Mode & lel & \\
\hline & & $\begin{array}{l}\text { input } \\
\text { air te } \\
\text { wind } \\
\text { relati }\end{array}$ & $\begin{array}{l}\text { uts } \\
\text { temperature } \\
\text { d speed } \\
\text { tive humidity }\end{array}$ & $\begin{array}{l}\mathrm{Rg} \\
\text { LAI } \\
\text { vegetation height }\end{array}$ \\
\hline
\end{tabular}

Most of those parameters are assigned from a priori averages taken from the literature for crop land use types and not optimized on the datasets used in this study. Soil heat flux is modeled as a fixed (0.3) fraction of the net radiation at the ground surface. We ignore here the phase shift between the diurnal fluctuations of the soil heat flux and the net radiation. While important around 10:00 LT and 16:00 LT, the resulting cumulative error is rather small at the daily scale (Gentine et al., 2007). The model allows us to easily compute the evolution of ETP at seasonal scale.

\section{Material and methods}

The various datasets used for testing both methods are described below. In order to apply the reconstruction algorithms for clear sky days only, the method to pick out these days in all time series is displayed first. In a third part, we present the arguments concerning the choice of the reference instantaneous estimates at the time of the satellite overpass to compute $\mathrm{EF}, \mathrm{SF}$ and $\mathrm{AE}$, as well as the algorithm selected to interpolate between two successive clear sky days.

\subsection{Experimental datasets}

Meteorological and flux data necessary to run and test both methods were obtained over several agricultural fields in different climates.

The first dataset was collected over two cultivated plots, Auradé $\left(43^{\circ} 54^{\prime} 97^{\prime \prime} \mathrm{N}, 01^{\circ} 10^{\prime} 61^{\prime \prime} \mathrm{E}\right)$ and Lamasquère $\left(43^{\circ} 49^{\prime} 65^{\prime \prime} \mathrm{N}, 01^{\circ} 23^{\prime} 79^{\prime \prime} \mathrm{E}\right)$, separated by $12 \mathrm{~km}$ and located near Toulouse (Southwest France). The second is situated near Sidi Rahal in the Haouz plain in Morocco $\left(31.67250^{\circ} \mathrm{N}\right.$, $7.59597^{\circ} \mathrm{W}$ ). The third one is in Avignon in southeastern France $\left(43.92^{\circ} \mathrm{N} ; 4.88^{\circ} \mathrm{E}\right)$. Auradé, Lamasquère and Avignon were part of the CarboEurope-IP Regional Experiment (Dolman et al., 2006) and the CarboEurope-IP Ecosystem Component. In that context, the data were used for analyzing $\mathrm{CO}_{2}$ surface-atmosphere exchanges and production of full crop rotation (e.g. Kutsch et al., 2010; Ceschia et al., 2010). For those sites, the Level 3 flux products (i.e. non gapfilled) were used. These datasets represent eleven crop cycles to be 
Table 2. Characteristics of the 11 datasets used in this study.

\begin{tabular}{lllrrlc}
\hline Site & year & crop & $\begin{array}{r}\text { Data set } \\
\text { (DOY) }\end{array}$ & $\begin{array}{r}\text { Number of } \\
\text { clear sky } \\
\text { days at } \\
\text { noon }\end{array}$ & $\begin{array}{l}\text { Vegetation } \\
\text { period } \\
\text { (DOY of } \\
\text { max LAI) }\end{array}$ & $\begin{array}{c}\text { Number of } \\
\text { stress } \\
\text { periods } \\
(>4 \text { days })\end{array}$ \\
\hline Auradé & 2005 & Rapeseed & $1-365$ & 164 & $1-181(118)$ & 2 \\
& 2006 & Wheat & $1-365$ & 183 & $1-174(122)$ & 2 \\
& 2007 & Sunflower & $1-273$ & 112 & $129-263(196)$ & 5 \\
\hline Lamasquère & 2005 & Triticale & $1-365$ & 107 & $20-187(133)$ & 2 \\
& 2006 & Corn & $1-365$ & 165 & $150-247(240)$ & 4 \\
& 2007 & Wheat & $1-273$ & 114 & $1-180(106)$ & 3 \\
\hline Morocco & 2003 & Wheat & $35-141$ & 36 & $35-141(111)$ & 2 \\
& 2004 & Wheat & $1-112$ & 77 & $1-112(97)$ & 6 \\
\hline \multirow{2}{*}{ Avignon } & 2004 & Wheat & $1-365$ & 242 & $35-173(97)$ & 1 \\
& 2005 & Peas & $1-365$ & 243 & $110-172(150)$ & 2 \\
& 2007 & Sorghum & $1-365$ & 240 & $141-240(185)$ & 2 \\
\hline
\end{tabular}

used for the evaluation of ET extrapolation and interpolation methods on a variety of rainfed and irrigated crops (Table 2).

The experimental setup collected standard meteorological measurements (global incoming radiation, wind speed, air temperature and humidity, rainfall). For each site, the different components (global solar radiation, reflected solar radiation, downward longwave radiation and upward longwave radiation) of the net radiation were measured using a CNR1 (Kipp \& Zonen, Delft, NL) radiometer. Soil heat fluxes were measured using heat flux plates close to the surface and a correction to account for the top soil transient heat storage fluctuations. Eddy covariance systems were used to obtain latent heat fluxes. The leaf area index (LAI) was measured using hemispherical photography (Demarez et al., 2008).

For a complete description of the site characteristics and more information on these datasets, see Beziat et al. (2009) for Auradé and Lamasquère, Boulet et al. (2007) for Morocco and Kpemlie (2009) for Avignon.

\subsection{Determination of clear sky days}

Cloud occurrence is an issue because no data is acquired under cloudy conditions in the TIR domain, which is the most appropriate way to assess actual evaporation and soil moisture status at relevant space and time scales (Boulet et al., 2007; Hain et al., 2009). Data availability depends therefore on both the overpass frequency (also referred to as revisit) and the cloud cover conditions. The extrapolation of ET from an instantaneous measurement to a daily value is computed for all clear sky days, which correspond to days for which remotely sensed data could be available.

To determine clear sky days for the different datasets, actual incoming solar radiation was compared to outputs of a theoretical clear sky radiation model. The combined Meeus (1999) and Bird and Hulstrom (1981) model (Fig. 3) was selected on the basis of the results obtained during the comparison of five models by Annear and Wells (2007). This empirical model incorporates different atmospheric transmissivity coefficients which can be adjusted for calibration. In this intercomparison, it was found that for both years (of study) the combined Meeus (1999) and Bird and Hulstrom (1981) model performed best. When the five models were calibrated to the entire clear sky dataset, the combined Meeus (1999) and Bird and Hulstrom (1981) model had the lowest Root Mean Square Error (RMSE). A constant ratio between clear sky and extraterrestrial radiances, as proposed by the FAO method, was also calibrated and is shown in Fig. 3 to illustrate the clear sky radiation course during the year according to earth-sun geometry only.

The combined Meeus (1999) and Bird and Hulstrom (1981) model requires air temperature, atmospheric radiation and relative humidity as inputs and the clear sky radiation is computed as the sum of direct and diffuse radiation components.

Clear sky days are selected on the basis of a critical value of the ratio between the incoming solar and the theoretical clear sky radiations. This threshold is not straightforward to define. Based on the comparison of this ratio with a second proxy of cloudiness, the ratio between the diffuse and the total Photosynthetically Active Radiation (PAR), measured in two amongst the three sites, it was established that if the observed radiation was higher than $85 \%$ of the computed clear sky radiation at a specific time corresponding to the choice of the time of the satellite overpass, the day could be defined as clear.

The days classified as clear according to this method were then compared with MODIS (Aqua) cloud mask products obtained at 13:30 LT. The model applied at 13:30 LT produces matching errors with MODIS masks from 6.52 to $11.72 \%$ 
(depending on sites). These errors are quite small. Therefore the model and the threshold were kept to select clear sky days for a satellite overpass at midday. One must note that the number of clear sky days does not change significantly when the time of overpass varies from 10:00 LT to 14:00 p.m. LT. This is in agreement with the work carried out by Lagouarde et al. (2012) for historical climatic data at five locations in France.

The performances of the following methods were assessed on a large dataset, whose characteristics are presented in Table 2 and which included $11 \mathrm{yr}$ of data on 3 different sites with different climates and different crop types.

In total, both methods to reconstruct daily ET were tested on data for more than 1600 different days.

\subsection{Instantaneous input data used for both EF and SF methods}

Remotely sensed methods to estimate daily ET strive to use as little ancillary data as possible (network of meteorological stations or outputs of climate models). They aim at routinely producing instantaneous $\mathrm{LE}$ at the time of satellite overpass using energy balance models, and either $\mathrm{AE}_{\mathrm{d}}$ or $\mathrm{ETP}_{\mathrm{d}}$ from remotely sensed and meteorological forcing data. In order to restrict our study to the test of the performance of the reconstruction methods of daily (extrapolation) and seasonal (interpolation) ET from sparse instantaneous estimates, we assume that LE and AE are perfectly known for all clear sky days at the time of the satellite overpass (which is taken at midday by default or otherwise stated in this study) and ignore the uncertainties associated with their estimation from energy balance models. This assumption also holds for all inputs to compute ETP since the latter cannot be measured in situ. We therefore use the true in situ LE values measured by eddy covariance and the true $\mathrm{AE}$ values measured on the ground by the net radiometer and the soil heat flux plates, both at the time of the TIR data acquisition, as well as the true input data for the ETP estimates. A diagram summarizing ET extrapolation methods is presented in Fig. 1a.

\subsection{Reconstruction of seasonal ET from instantaneous latent heat flux on clear sky days}

Once ET has been extrapolated from an instantaneous to a daily time scale, one needs to interpolate daily ET between the dates of two successive image acquisitions. The classical approach is to perform a linear interpolation of EF and SF between two successive (clear) days of data and to multiply EF or SF by AE or ETP (respectively) values computed during the intermediate cloudy days (Fig. 1b).

To estimate $\mathrm{AE}_{\mathrm{d}}$ on cloudy days, when RS data are not available, the ratio between daily $\mathrm{AE}_{\mathrm{d}}$ (computed from Eq. 3 ) and daily $R_{\mathrm{g}_{\mathrm{d}}}$ (obtained from a nearby meteorological station) is interpolated linearly between the closest previous and following clear sky days, respectively.
Then, by applying successively the interpolation and extrapolation algorithms based either on EF or SF, seasonal ET can be simulated. In what follows, the same factor (either EF or SF) is used for consistency for both interpolation and extrapolation. We did not test a combination of both methods (EF for extrapolation and SF for interpolation or SF for extrapolation and $\mathrm{EF}$ for interpolation).

Moreover, the study is focused on the reconstruction of ET over an entire growing season, which usually covers several months. However, for some discussions (say, on the optimum revisit frequency), this criteria may not be the most relevant and another time scale should be considered. For irrigation monitoring or water stress detection, for instance, a shorter timescale, typically that of an average interstorm, should be looked at but this is beyond the scope of this particular study, and would not be feasible with the limited number of water stress events sampled in the various datasets.

Finally, two auxiliary but nonetheless important issues addressed in the discussion section are presented below: one is related to interpreting differences in performances for both methods as a function of water stress; the second is related to the specification of future satellite platform overpass time and revisit.

\subsection{Determination of stress periods}

Identification method of stress periods is particularly interesting to discuss our results. It has been shown in other studies that most extrapolation and interpolation methods have contrasting performances whether water stress is present or not. The number of stress periods is determined considering observed evapotranspiration data. A water stress period is identified on the following basis: stress starts when a large deviation between the potential evapotranspiration ETP and the measured actual evapotranspiration rates is observed away from any rain event or any other income of water (i.e. irrigation) and ends with the next income of water. When this deviation is observed for more than 4 days in a row, we arbitrarily define the period as stressed.

\subsection{Reference overpass time and revisit}

The different instantaneous in situ data (used here as substitutes for the instantaneous estimates that could be later on derived from RS data at the time of satellite overpass) are taken at midday by default. According to Gentine et al. (2007), midday is the most representative hour to reconstruct ET from the EF.

This hypothesis is discussed in a later section. The reconstruction performance of daily ET from a one-time day measurement is tested for times of day ranging from 10:00 LT to 14:00 LT.

To address the seasonal reconstruction of ET from RS data specifically, the impact of different revisits on the performances of the two methods is also tested from 1 to 16 days. 

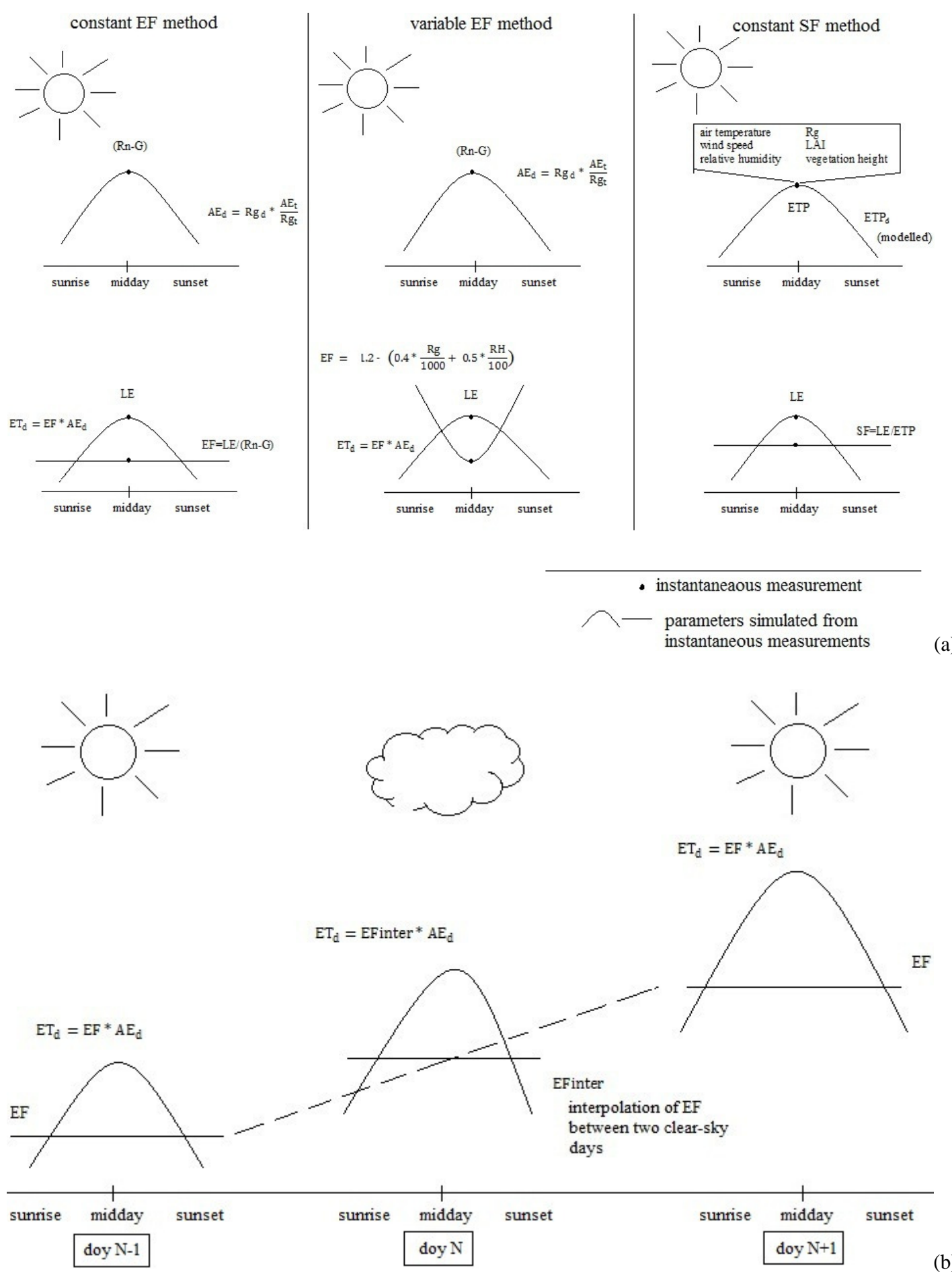

(b)

Fig. 1. Illustration of EF and SF methods to retrieve daily and seasonal ET. (a) Illustration of EF and SF methods to reconstruct daily ET from instantaneous measurements and (b) illustration of method to retrieve ET on cloudy days.

\section{Results}

Since each method is primarily dependent on the model accuracy to compute the available energy (AE) and potential evapotranspiration (ETP) instantaneous rates and daily averages, we first show the model performance in estimating those quantities. Then the results of both EF and SF methods in reconstructing daily ET are presented, together with the impact of the time of satellite overpass and the time of revisit on this performance, because once again these methods are 


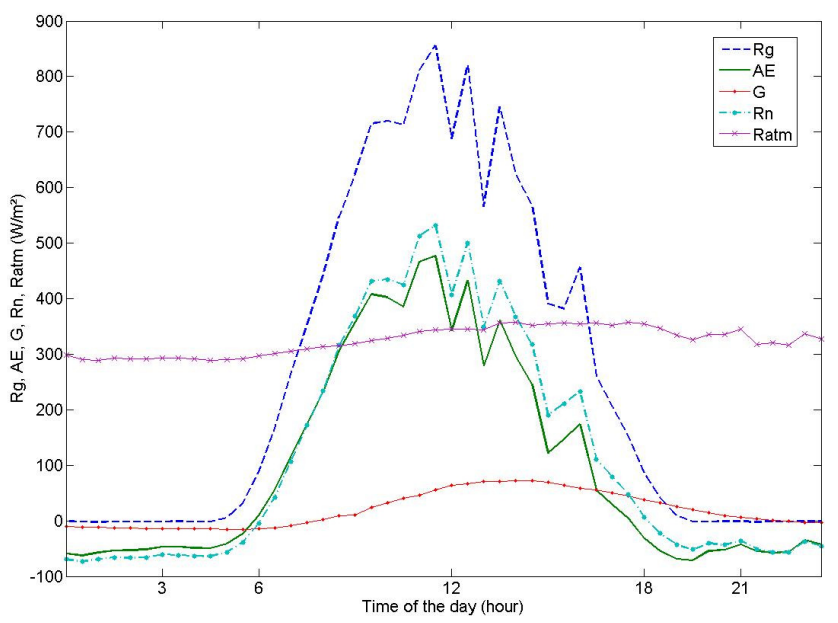

Fig. 2. Illustration of the typical course of $\mathrm{AE}, R_{\mathrm{g}}, G, R_{\mathrm{n}}$ and $R_{\mathrm{atm}}$ during a day (doy 124, Auradé 2006).

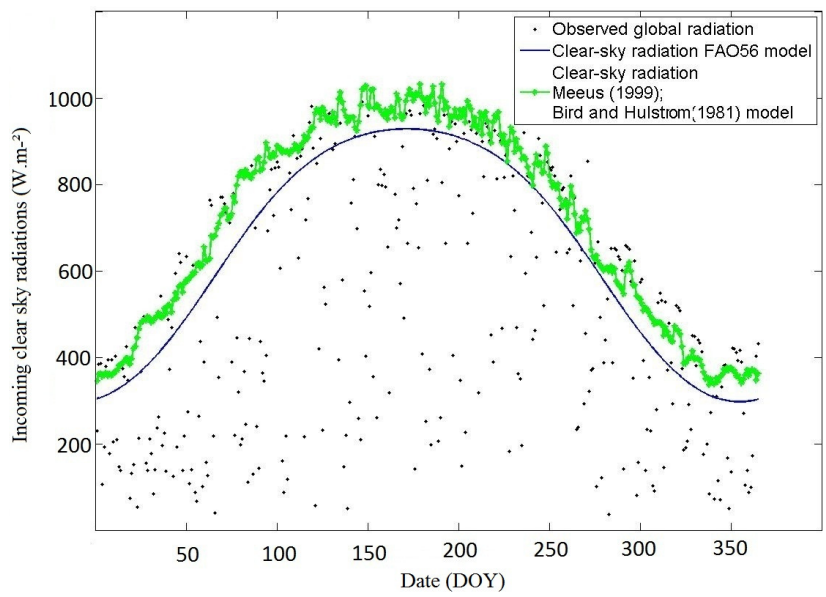

Fig. 3. Observed vs. estimated clear sky radiations at noon using FAO and combined Meeus and Bird and Hulstrom model for Lamasquère 2007.

meant to be applied operationally using RS data. The interest of a proposed improvement of the classical EF method is also shown for daily ET reconstruction. Eventually, a similar analysis is carried out for the seasonal ET reconstruction.

\subsection{Reconstruction of daily ET from instantaneous estimates on clear sky days}

\subsubsection{Daily available energy}

An overestimation of about $10 \%$ is found between estimated (Eq. 3) and measured daily components of the available energy (Fig. 4).

Subsequently, the following corrected parameterization of $\mathrm{AE}$ is used:

$\mathrm{AE}_{\mathrm{d}}=0.9 \cdot R_{\mathrm{g}_{\mathrm{d}}} \cdot \frac{\mathrm{AE}_{t}}{R_{\mathrm{g}_{t}}}$.

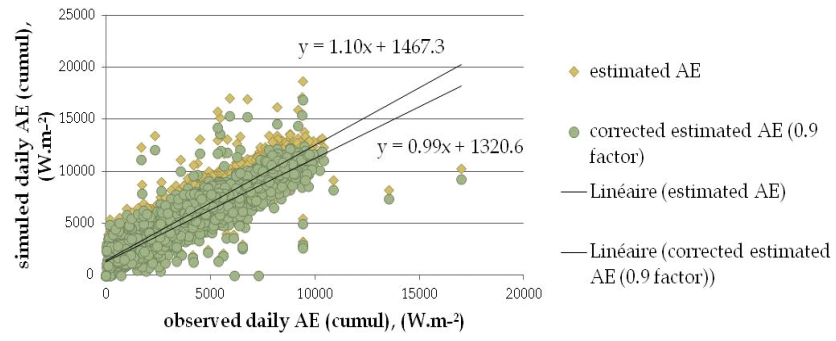

Fig. 4. Comparison of estimated AE (from Eq. 3) and corrected AE (from Eq. 6). All data and all sites are considered.

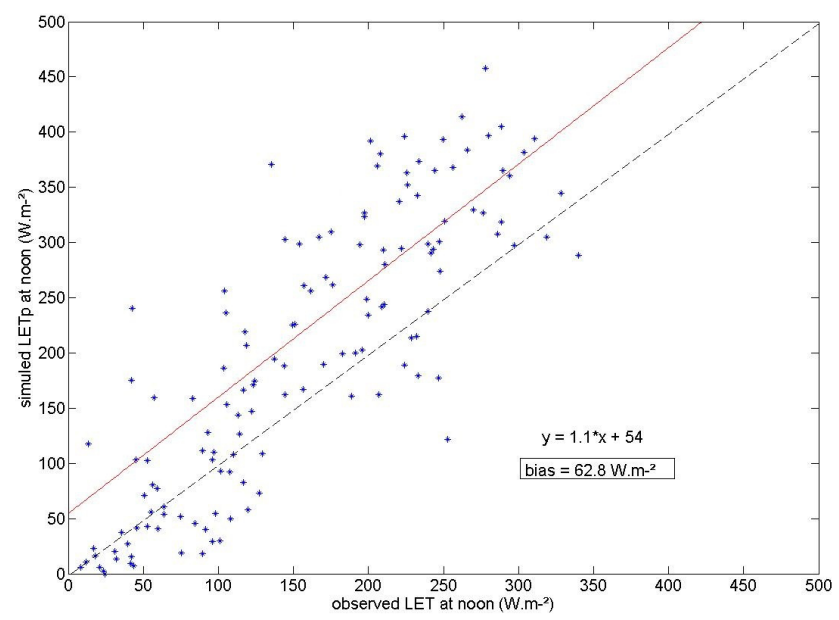

Fig. 5. Observed ET at noon compared with simulated ETP on unstressed days, example for Auradé 2006.

With Eq. (6), biases between simulated and observed ET are reduced by $25 \%$ up to $40 \%$ (depending on sites) compared to Eq. (3). RMSE values are also reduced by $18 \%$ on average. Nash-Sutcliffe efficiency fluctuates between 0.4 and 0.6 when using Eq. (6) instead of 0.28 and 0.4 if Eq. (3) is used. The corrected parameterization (Eq. 6) leads to a RMSE as low as $38 \mathrm{~W} \mathrm{~m}^{-2}$ on average for every site.

It must be pointed out that diurnal values only are used to compute all statistics. Diurnal values are selected on the basis of a threshold on incoming solar radiation values $\left(R_{\mathrm{g}}>10 \mathrm{~W} \mathrm{~m}^{-2}\right)$.

\subsubsection{ETP simulation model}

This uncalibrated model performs relatively well for unstressed periods corresponding to the interval between an irrigation or a rainfall event and the occurrence of water stress or the next income of water, whichever comes first. For those days there is a bias at noon ranging between $44.5 \mathrm{~W} \mathrm{~m}^{-2}$ and $87.5 \mathrm{~W} \mathrm{~m}^{-2}$, depending on the dataset.

Figure 5 shows a scatterplot of computed ETP compared with observed ETP at noon during unstressed periods for the Auradé dataset in 2006. One can note that, with the chosen 
default values of the parameters, the model performs effectively well but tends to overestimate ETP.

\subsubsection{EF and SF extrapolation methods}

Both methods show similar performances for the reconstruction of daily ET from an instantaneous measurement at midday on sites exhibiting few water stress events (Table 3). On these sites, the EF method shows global RMSE of $0.78 \mathrm{~mm} \mathrm{day}^{-1}$ while global RMSE is $0.73 \mathrm{~mm} \mathrm{day}^{-1}$ for the SF method. The mean bias on those unstressed sites calculated for EF method is $-0.39 \mathrm{~mm} \mathrm{day}^{-1}$ and $-0.31 \mathrm{~mm} \mathrm{day}^{-1}$ for the SF method. However, the method based on EF tends to outperform the method based on SF for most sites that exhibit a significant water stress level (Auradé 2007, Lamasquère 2006 and 2007, Morocco 2004). For Auradé 2007, a site presenting 5 stress periods, RMSE is $0.60 \mathrm{~mm} \mathrm{day}^{-1}$ when ET is reconstructed with the EF method, and $0.81 \mathrm{~mm} \mathrm{day}^{-1}$ with the SF method. For this site, the EF method leads to an efficiency of 0.70 , whereas the SF method leads to an efficiency of 0.30 .

For those datasets, the EF method shows a very small bias (absolute value less than $0.11 \mathrm{~mm} \mathrm{day}^{-1}$ ), whereas the bias is commonly greater on other sites. A similar observation can be made for RMSE values $\left(0.45 \mathrm{~mm} \mathrm{day}^{-1}\right.$ average for sites with water stress, $0.65 \mathrm{~mm} \mathrm{day}^{-1}$ elsewhere). For Auradé, in 2007, where we detect a significant number of 5 water stress periods, RMSE values between observed and simulated ET are $0.6 \mathrm{~mm} \mathrm{day}^{-1}$ when calculated with the EF method and $0.81 \mathrm{~mm} \mathrm{day}^{-1}$ when using the SF method.

\subsubsection{Impact of the time of overpass on the daily reconstruction}

Up to now, all methods use instantaneous data acquired around noon. In what follows we want to assess the impact of overpass time on the reconstruction of the diurnal cycle. Both methods were tested for different hours of overpass in order to estimate the most relevant hour to scale diurnal ET.

We observed that the number of available data is similar from 10:00 LT to 14:00 LT for each site.

Figure 6 shows the influence of the time of overpass on the estimation of the cumulative amount of water lost through evaporation at seasonal scale when the EF extrapolation method is applied. The sum corresponds to all clear sky days since the extrapolation method can only be applied for those conditions. The Nash-Sutcliffe efficiency between the reconstructed and the observed seasonal evapotranspiration for the same selection of clear sky days peaks at noon. It is shown that the actual water lost through evapotranspiration is underestimated by 5 to $18 \%$ (depending on the sites) at noon by our model. This underestimation increases with an earlier or later time of overpass (from 14 to $37 \%$ at 10:00 LT), except for two sites. This underestimation remains relatively small within the 11:00 LT to 13:00 LT time frame.

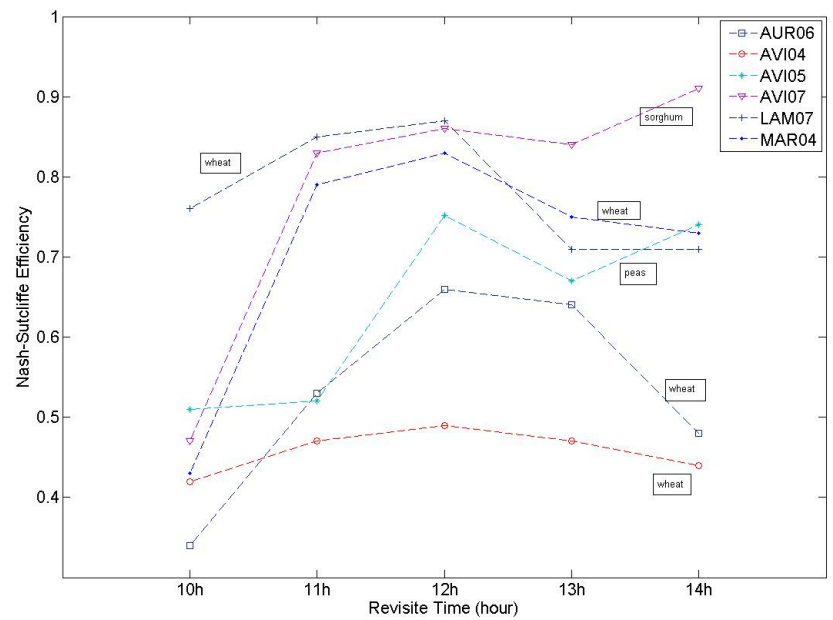

Fig. 6. Evolution of the Nash-Sutcliffe Efficiency for evapotranspiration estimation using instantaneous estimates at different times of acquisition.

\subsection{Improvement of EF method when taking into account EF diurnal fluctuations}

In our study, we did not find a consistent pattern for SF diurnal fluctuations. This might be due to the variable discrepancies between stomatal functioning in actual and potential conditions, respectively. Again, in order to select one operational method for daily and seasonal ET reconstruction, we decided to improve the best performing method (the EF method) with the known diurnal shape of EF instead of self preservation.

We test the bivariate linear relationship proposed by Hoedjes et al. (2008) to parameterize the EF diurnal cycle (Eq. 4) since one can expect with this parameterization a large improvement of the classical method to reconstruct daily ET $\left(\mathrm{ET}_{\mathrm{d}}\right)$ from instantaneous EF estimates. This parameterization depends on two routinely available atmospheric forcing parameters, the incoming solar radiation and the relative humidity of the air. In order to be consistent with the previous parameterizations, a variation of Eq. (4) is used here to account for the bias observed in the reconstruction of daily AE:

$\mathrm{EF}=\left[1.2-\left(0.4 \cdot \frac{R_{\mathrm{g}}}{1000}+0.5 \cdot \frac{\mathrm{RH}}{100}\right)\right] \cdot\left(\frac{\mathrm{EF}_{12 \mathrm{obs}}}{\mathrm{EF}_{12 \mathrm{sim}}}\right) \cdot 1.1$.

The coefficient 1.1 corrects for the overestimation of diurnal $\mathrm{AE}$ when instantaneous AE at midday is used (see Sect. 4.1.1 and Anderson et al., 1997).

With this parameterization (called "EF-variable method" in Fig. 7) of the concave-up shape of EF during the day, an important improvement can also be observed for all but one datasets. This is particularly true when looking at the water lost through ET during the season (Table 5).

It is shown that ET is underestimated by an average of $15.8 \%$ using constant EF. The error is reduced to an average 
Table 3. EF and SF methods performance statistics for clear sky days and an everyday revisit frequency.

\begin{tabular}{|c|c|c|c|c|c|c|c|c|}
\hline \multirow{2}{*}{$\begin{array}{l}\text { Site } \\
\text { method }\end{array}$} & \multicolumn{2}{|c|}{$\operatorname{RMSE}\left(\mathrm{mm}\right.$ day $\left.^{-1}\right)$} & \multicolumn{2}{|c|}{$E$} & \multicolumn{2}{|c|}{$\operatorname{Bias}\left(\mathrm{mm}_{\mathrm{day}}{ }^{-1}\right)$} & \multicolumn{2}{|c|}{$\operatorname{MAE}\left(\mathrm{mm} \mathrm{day}^{-1}\right)$} \\
\hline & $\mathrm{EF}$ & SF & $\mathrm{EF}$ & SF & $\mathrm{EF}$ & $\mathrm{SF}$ & $\mathrm{EF}$ & SF \\
\hline Auradé, 2006 & 0.45 & 0.73 & 0.57 & 0.61 & 0.01 & -0.24 & 0.55 & 0.55 \\
\hline Auradé, 2007* & $0.60^{*}$ & $0.81^{*}$ & $0.71^{*}$ & $0.30^{*}$ & $-0.11^{*}$ & $-0.59^{*}$ & $0.38^{*}$ & $0.64^{*}$ \\
\hline Lamasquère, 2006* & $0.54^{*}$ & $0.75^{*}$ & $0.75^{*}$ & $0.61^{*}$ & $-0.05^{*}$ & $-0.55^{*}$ & $0.41^{*}$ & $0.60^{*}$ \\
\hline Lamasquère, 2007* & $0.43^{*}$ & $1.53^{*}$ & $0.87^{*}$ & $0.50^{*}$ & $-0.07^{*}$ & $0.30^{*}$ & $0.32^{*}$ & $0.90^{*}$ \\
\hline Morocco, 2004* & $0.26^{*}$ & $0.27^{*}$ & $0.76^{*}$ & $0.85^{*}$ & $-0.06^{*}$ & $-0.02^{*}$ & $0.28^{*}$ & $0.22^{*}$ \\
\hline Avignon, 2004 & 0.86 & 0.81 & 0.53 & 0.73 & -0.65 & -0.38 & 0.72 & 0.61 \\
\hline Avignon, 2005 & 0.74 & 0.57 & 0.75 & 0.86 & -0.54 & -0.39 & 0.57 & 0.43 \\
\hline Avignon, 2007 & 0.53 & 0.82 & 0.85 & 0.71 & -0.36 & -0.23 & 0.43 & 0.47 \\
\hline
\end{tabular}

* Site presenting more than 2 stressed periods ( $>4$ days of stress). RMSE: $\sqrt{\frac{1}{n} \sum_{k=1}^{n}\left(Y_{k}^{\text {est }}-Y_{k}^{\text {obs }}\right)^{2}}$ Bias: $\frac{1}{n} \sum_{k=1}^{n}\left(Y_{k}^{\text {est }}-Y_{k}^{\text {obs }}\right)$ $E$ (Nash efficiency): $1-\frac{\sum_{k=1}^{n}\left(Y_{k}^{\text {est }}-Y_{k}^{\text {obs }}\right)^{2}}{\sum_{k=1}^{n}\left(Y_{k}^{\text {est }}-\bar{Y}_{k}^{\text {obs }}\right)^{2}}$ MAE: $\frac{1}{n} \sum_{k=1}^{n}\left|Y_{k}^{\text {est }}-Y_{k}^{\text {obs }}\right|$ $n$ : number of observation

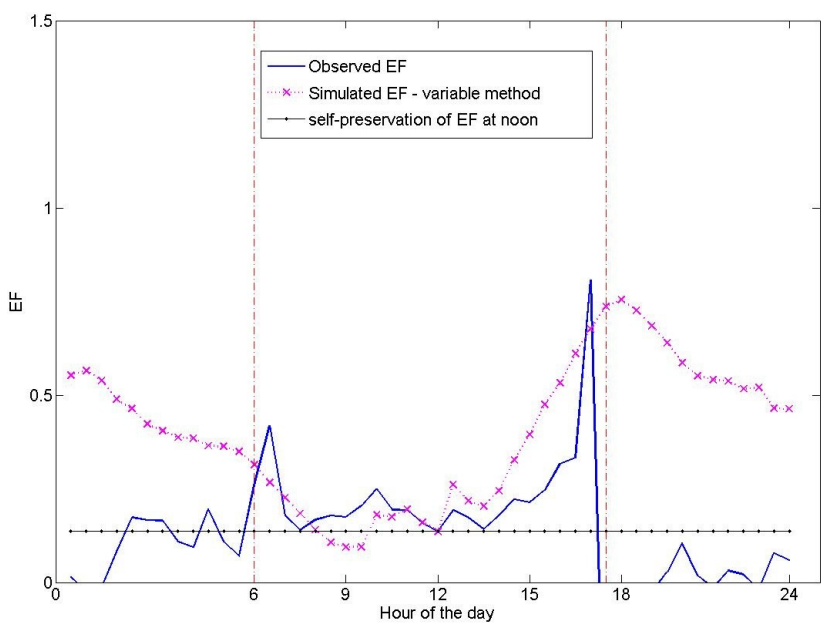

Fig. 7. Observed and simulated (Eq. 7) EF diurnal fluctuations: example for day of year 73 for the Morocco 2004 dataset.

of $6.5 \%$ using the variable EF parameterization (Eq. 7), which is typically lower than measurements errors.

\subsection{Impact of revisit frequency}

\subsubsection{Seasonal ET reconstruction for an everyday revisit}

According to Fig. 8, with a revisit frequency of one day, the water stress is often overestimated when performing a linear interpolation between two successive days of available data; therefore, the resulting reconstructed ET is underestimated. Results show indeed a significant underestimation of ET at seasonal scales, with cumulative differences of more than $50 \mathrm{~mm}$ for some sites as Auradé in 2007, Avignon in 2004 or Lamasquère in 2006 (Table 4).

SF method displays the largest underestimation in ET estimations (Fig. 8).

\subsubsection{Seasonal ET reconstruction performances for lower revisit frequencies}

Up to now it was assumed that an instantaneous estimate is available for each clear sky day, which corresponds to an everyday revisit frequency. In this section we analyze the evolution of the performances of both methods when selecting different revisit frequencies, from 1 day (typical of many low resolution satellites such as MODIS) to 16 days (typical of many higher resolution satellites such as Landsat).

One expects that performances of the interpolation algorithm will drop significantly when the time lag between two successive acquisitions increases as a result of the combined revisit and cloud occurrence frequencies. In fact, results for the chosen performance criterion, the cumulative seasonal evapotranspiration, do not consistently deteriorate when the revisit frequency increases up to 10 days, and are very close to the 1 day revisit performances. This is illustrated in Fig. 9.

Moreover, for most datasets exhibiting water stress, the performance criteria vary rather chaotically from one frequency to the other (Fig. 9a). On sites evaporating mostly at a potential rate (Fig. $9 \mathrm{~b}-\mathrm{c}$ ), results do not vary significantly with the revisit frequency, even if we can point out that after 

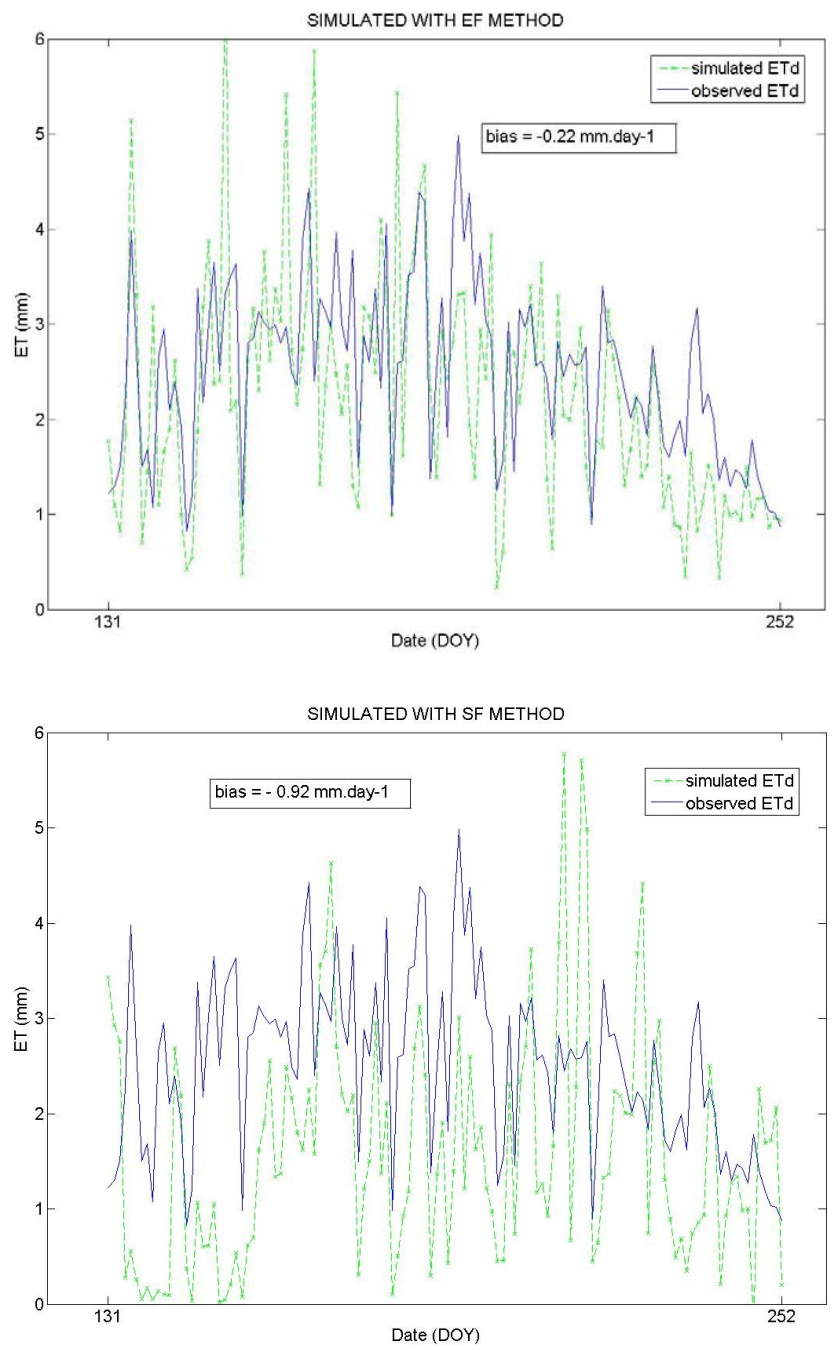

Fig. 8. Daily ET simulated with SF and EF methods for the Auradé 2007 dataset, for clear sky days and an everyday revisit frequency.

10 days of revisit, the performances of the interpolation algorithm drop significantly. The EF method outperforms the SF method at any revisit frequency, and the deterioration with increasing revisit frequency is more pronounced for the SF method.

\subsubsection{Impact of the time of overpass on seasonal ET reconstruction}

Impacts of the time of overpass on seasonal reconstruction performances are in agreement with those presented in Sect. 4.1.4. For each revisit frequency, it appears that noon is the most representative hour to reconstruct seasonal ET. Again, the criterion used to assess the performance is the difference between observed and simulated seasonal cumulative evapotranspiration.

One can note that with an earlier (or later) time of overpass, results are more significantly and quickly deteriorated,
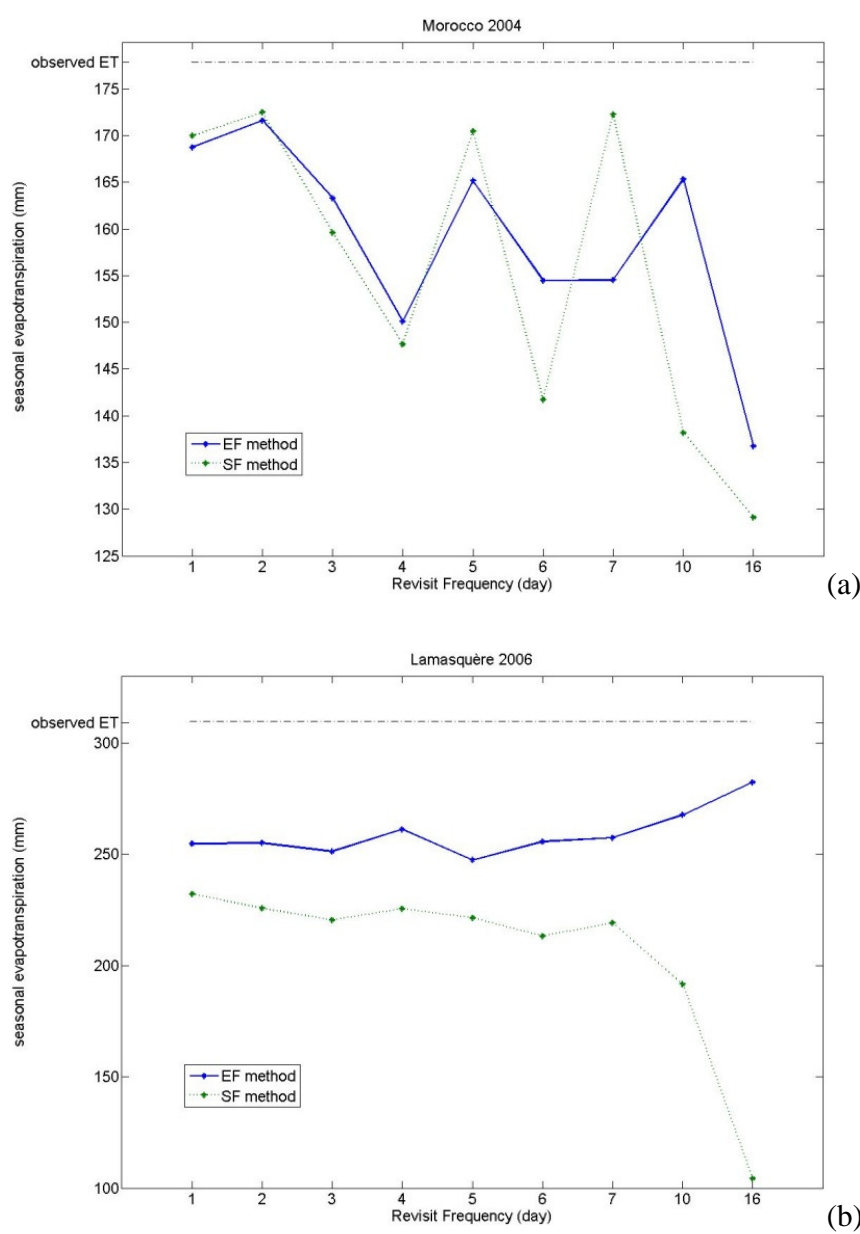

(b)

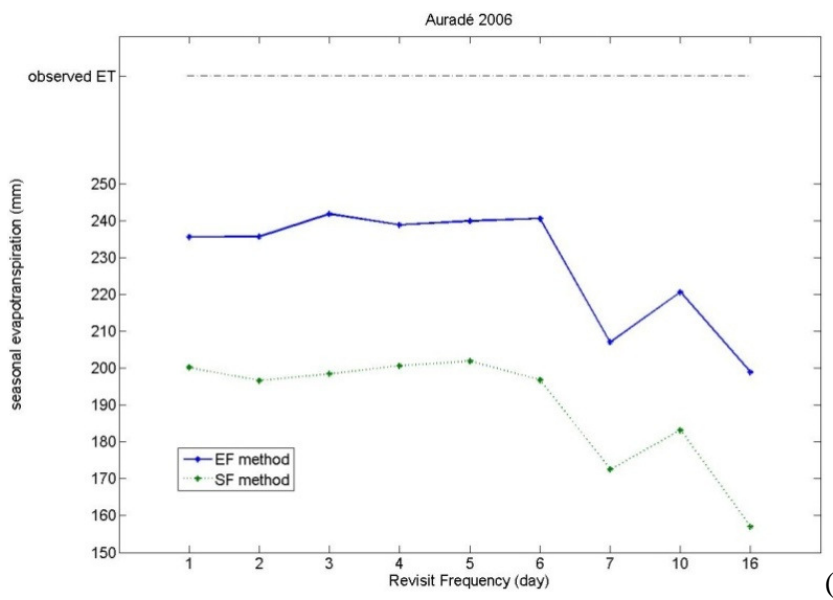

(c)

Fig. 9. Seasonal cumulative evapotranspiration as a function of revisit frequency. (a) Morocco 2004, (b) Lamasquẽre 2006 and (c) Auradé 2006. 
Table 4. Seasonal ET (mm) simulated with EF and SF methods for an everyday revisit frequency.

\begin{tabular}{|c|c|c|c|}
\hline & $\begin{array}{c}\text { observed } \\
\text { ET } \\
(\mathrm{mm})\end{array}$ & $\begin{array}{c}\text { simulated } \\
\text { ET } \\
\text { with } \\
\text { EF } \\
\text { method } \\
(\mathrm{mm})\end{array}$ & $\begin{array}{c}\text { simulated } \\
\text { ET } \\
\text { with } \\
\text { SF } \\
\text { method } \\
(\mathrm{mm})\end{array}$ \\
\hline Auradé, 2006 & 279.1 & 235.5 & 200.1 \\
\hline Auradé, 2007 & 305.9 & 248.3 & 209.4 \\
\hline Lamasquère, 2006 & 309.7 & 254.7 & 232.1 \\
\hline Lamasquère, 2007 & 453.4 & 340.8 & 301.1 \\
\hline Morocco, 2004 & 177.8 & 168.7 & 169.9 \\
\hline Avignon 2004 & 371.8 & 283.1 & 297.4 \\
\hline Avignon, 2005 & 178.2 & 133.1 & 115.5 \\
\hline Avignon, 2007 & 256.5 & 171.7 & 197.1 \\
\hline
\end{tabular}

but the general trend remains the same as when data are acquired at noon.

\section{Discussion}

$\mathrm{AE}_{\mathrm{d}}$ and $\mathrm{ETP}_{\mathrm{d}}$ models perform well, but there is an overestimation of daily $A E_{d}$. An overestimation of the same order of magnitude has been also reported by Anderson et al. (1997) on a different dataset. This could be explained by the timeshift of the soil heat flux, which peaks midmorning, but further research is required to confirm the physical reasons behind this overestimation. Anyway, this rather simple parameterization (Eq. 6) seems to be systematic enough to be routinely used in the modeling framework presented in Anderson et al. (1997).

The comparable performances of the EF and SF methods for daily ET reconstruction are consistent with most previous studies. The large improvement for the results of the EF method, when taking into account the empirical formulation for the diurnal fluctuations of EF proposed by Hoodjes et al. (2008) for unstressed vegetation, is also consistent with the consensus amongst authors on the observed or simulated concave-up shape of most EF diurnal fluctuations, even though other shapes (incl. tangential) have been described in the literature (see for example Van Niel et al., 2011). The parameterization (Eq. 7) built for an olive orchard was tested for our datasets, which are all crops. It improves greatly the reconstruction of daily ET for all sites and the large number of climatologic conditions sampled in our datasets.

In our case, since most sites exhibit little water stress, the shape reproduced by Eq. (7) fits well the observed concaveup shape of EF. Since water stress is the exception rather than the rule for most vegetation around the globe (especially if one assumes that this method targets mostly agricultural applications), one can expect that the method will perform generally well and provide a robust correction of bias at
Table 5. RMSE and cumulative seasonal evapotranspiration for clear sky days simulated with constant or variable EF.

\begin{tabular}{|c|c|c|c|c|}
\hline Site & Method & $\begin{array}{c}\text { RMSE } \\
\left(\mathrm{mm} \mathrm{day}^{-1}\right)\end{array}$ & $\begin{array}{l}\text { Water lost } \\
\text { through ET } \\
\text { on clear } \\
\text { sky days, } \\
\text { (measured/ } \\
\text { observed) } \\
(\mathrm{mm})\end{array}$ & $\begin{array}{l}\text { Error } \\
\text { in \% }\end{array}$ \\
\hline \multirow[t]{2}{*}{ Auradé, 2006} & constant & 0.45 & $194.1 / 251.2$ & 22.7 \\
\hline & Variable & 0.33 & $242.1 / 251.2$ & 3.6 \\
\hline \multirow[t]{2}{*}{ Auradé, 2007} & constant & 0.60 & $143.6 / 188.0$ & 23.8 \\
\hline & Variable & 0.36 & 188.6/188.0 & 0.0 \\
\hline \multirow[t]{2}{*}{ Lamasquère, 2006} & constant & 0.54 & $221.0 / 279.7$ & 21.0 \\
\hline & Variable & 0.54 & $285.5 / 279.7$ & -2.1 \\
\hline \multirow[t]{2}{*}{ Lamasquère, 2007} & constant & 0.43 & $182.3 / 194.3$ & 6.1 \\
\hline & Variable & 0.74 & $225.4 / 194.3$ & -16.3 \\
\hline \multirow[t]{2}{*}{ Avignon, 2004} & constant & 0.90 & $204.8 / 243.1$ & 15.8 \\
\hline & Variable & 0.83 & $217.1 / 243.1$ & 10.7 \\
\hline \multirow[t]{2}{*}{ Avignon, 2005} & constant & 0.75 & $94.5 / 117.5$ & 19.5 \\
\hline & Variable & 0.63 & $103.7 / 117.5$ & 11.7 \\
\hline \multirow[t]{2}{*}{ Avignon, 2007} & constant & 0.54 & $160.0 / 179.2$ & 10.7 \\
\hline & Variable & 0.47 & $174.3 / 179.2$ & 2.7 \\
\hline \multirow{2}{*}{ Maroc, 2004} & constant & 0.26 & $117.8 / 126.74$ & 7.0 \\
\hline & variable & 0.27 & $120.4 / 126.74$ & 5.0 \\
\hline
\end{tabular}

seasonal timescales. For most sites where water stress conditions are encountered, the observed shape of EF in stressed conditions is flatter during daytime, which is also consistent with previous studies. To improve the method, a Boolean index of the presence or not of water stress could be used to select the best parameterization of EF (constant or concaveup shape) to use to reconstruct ET for a given period.

If daily reconstruction from an instantaneous estimate is rather successful with both methods, none of the classical methods proposed to interpolate between days performs satisfactorily. Actually, assuming that SF or EF can be linearly interpolated between two successive clear sky days in order to compute SF or EF (respectively), values during cloudy days can be discussed. For those days indeed, SF and EF are often higher than what would happen if full radiation was available: during cloudy or overcast days, the evaporation process can be limited by the low available energy (energy limited evaporation), while during the previous and the following clear sky days, the available energy and thus the ETP rate are large enough to produce water stress (soil controlled evaporation). Moreover, the ratio which defines SF or EF does not have a real typical course during cloudy sky conditions, and this sometimes has a large impact on the performance of the daily ET reconstruction algorithm for cloudy days.

During cloudy sky periods, AE has a similar diurnal course as $R_{\mathrm{g}}$ and the evolution of the $\mathrm{EF}$ ratio is closer to reality than 
the evolution of SF ratio when performing a linear interpolation, meaning that the EF method is more relevant.

What can be observed is that the negative bias between computed and actual SF is greater than the bias between computed and actual EF. This can be partly explained by the fact that $\mathrm{AE}$ is similar in stressed and unstressed conditions, whereas ET drops significantly while ETP often increases significantly at the same time during stressed conditions. Inaccurate prediction of stress through temporal interpolation leads therefore to higher discrepancies for the SF method than for the EF method.

This might also be due to the interpolation of low evapotranspiration values at the beginning of the growing season corresponding to low EF and SF values. Robustness of the ETP simulation model, especially for bare soils, can also be questioned. The results obtained to compute water lost through evapotranspiration (i.e. a seasonal accumulation in $\mathrm{mm}$, Table 4) on sites exhibiting several periods of water stress are improved when using the EF method and in particular when extrapolation and interpolation are combined to compute seasonal evapotranspiration. Indeed, for sites where the largest underestimation of ET is observed, we can note that the gap is greater when ET is modeled with the SF method than with the EF method. For instance, for Auradé in 2007, the EF method underestimates actual ET by $57 \mathrm{~mm}$, while the SF method produces an underestimation of $95 \mathrm{~mm}$. For Lamasquère in 2006, actual ET is underestimated by $55 \mathrm{~mm}$ with the EF method and by $77 \mathrm{~mm}$ with the SF method.

One of the auxiliary goals of this paper is to investigate the impact of the time of overpass and the satellite revisit on the performance of daily and seasonal ET reconstruction. The optimum time of overpass is noon, which is in agreement with the theoretical study of Gentine et al. (2011) based on an analytical estimation of peak latent heat flux as a response to a sinusoidal radiation forcing. However, we did not find objective reasons for the good performances for afternoon overpass times for Avignon in 2005 (peas) and 2007 (sorghum).

The results for the optimum revisit frequency, which show no important variation in performance levels below one week between two successive image acquisitions, is more surprising but can be explained. Indeed, when the revisit frequency is greater than one day, some clear sky days are not observed and therefore some water stress periods are not detected. But this lack of detection does not occur for each combination of observed clear sky days. Again, the chosen criterion (the seasonal cumulative ET) is perhaps not the best one to investigate the optimum revisit strategy, since errors tend to be smoothed out at the monthly scale. It therefore represents "climatological errors".

\section{Conclusions}

Two methods to reconstruct daily and seasonal evapotranspiration from an instantaneous estimate at the time of satellite overpass during clear sky days were compared. Both methods were tested on a large range of sites and vegetation types under contrasted climatic conditions.

One uses the evaporative fraction (EF) as a proxy to extrapolate instantaneous ET to daily values by assuming self preservation of EF during the day and a linear algorithm to interpolate between two successive clear sky days; the second method is based on the self preservation of the stress factor (SF), which needs more input data and cannot be derived from RS data only. We found that for sites with no more than two periods of water stress longer than four days, EF and SF reconstruction methods exhibit similar performances.

However, for sites with a larger number of water stress periods, the EF method tends to outperform the SF method both for daily and seasonal reconstruction. Furthermore, the extrapolation results are significantly improved by modifying the parameterization of EF in order to take into account the diurnal fluctuations of EF following an empirical bilinear function of solar radiation and relative humidity of the air. An improved parameterization of SF could also be used, but a consistent diurnal shape of SF is difficult to find, a fortiori to parameterize. More research is needed to understand the daily behavior of SF with respect to stomatal conductance or plant microclimate.

Both methods could be improved by reducing the bias due to errors in the ETP simulation model (SF method) or AE simulation model (EF method). For the second (SF) method, the energy balance model used to compute ETP could be improved, for example by tuning some of the unknown parameters (e.g. minimum resistance) in order to minimize the difference between the surface temperature in potential conditions and the observed remotely sensed radiative temperature in unstressed conditions. For the first method, the universality of the empirical correction factor of about $10 \%$ calculated when modeling AE should be tested on a wider range of surface and climatic conditions.

Finally, the EF method to reconstruct daily and seasonal ET has been tested here with in situ data. In order to evaluate the method when using real remote sensing data, a study including errors on instantaneous EF when the later is derived from remote sensing model needs to be carried out.

Acknowledgements. Fundings from the French space agency (Centre National d'Etudes Spaciales, CNES) for the MiSTIGRI (MicroSatellite for Thermal Infrared Ground surface Imaging) phase A study, the MISTRALS (Mediterranean Integrated STudies at Regional And Local Scales) SICMed (Continental Surfaces and Interfaces in the Mediterranean area) program and the European FP7 project Sirrimed (FP7-KBBE-2009-3 Grant Agreement Number 245159) are gratefully acknowledged. Avignon and SudOuest data were acquired and processed in the frame of the 
CARBOEUROPE-IP and the CARBOFRANCE project funded by the European FP7 Program (GOCECT-2003-505572) and the French Ministry in charge of Environment (GICC programme). For the $\mathrm{R} 3$ dataset, in addition to IRD, financial support was provided by EC in the frame of the WATERMED project (contract ICA3CT-1999-00015) and IRRIMED project (contact ICA3-200210080) and by the French Programme National de Télédétection Spatiale (PNTS) and the French space agency (CNES).

Edited by: B. Su

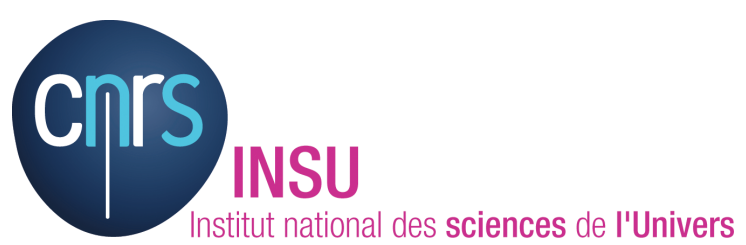

The publication of this article is financed by CNRS-INSU.

\section{References}

Allen, G., Pereira, L., Raes, D., and Smith, M.: Crop evapotranspiration - Guidelines for computing crop water requirements, FAO Irrigation papers, 56, Rome, Italy, 300 pp.,1998.

Allen, R. G., Tasumi, M., and Trezza, R.: Satellite-based energy balance for mapping evapotranspiration with internalized calibration (METRIC) - Model, J. Irrig. Drain. Eng.-ASCE, 133, 380-394, 2007.

Anderson, M. C., Norman, J. M., Diak, G. R., Kustas, W. P., and Mecikalski, J. R.: A two-source time-integrated model for estimating surface fluxes using thermal infrared remote sensing. Remote Sensing of Environment, 60, 195-216, 1997.

Anderson, M. C., Kustas, W. P., Norman, J. M., Hain, C. R., Mecikalski, J. R., Schultz, L., González-Dugo, M. P., Cammalleri, C., d'Urso, G., Pimstein, A., and Gao, F.: Mapping daily evapotranspiration at field to continental scales using geostationary and polar orbiting satellite imagery, Hydrol. Earth Syst. Sci., 15, 223-239, doi:10.5194/hess-15-223-2011, 2011.

Annear, R. L. and Wells, S. A.: A comparison of five models for estimating clear-sky solar radiation, Water Resour. Res., 43, W10415, doi:10.1029/2006WR005055, 2007.

Bastiaanssen, W. G. M., Menenti, M., Feddes, R. A., and Holtslag, A. A. M.: A remote sensing surface energy balance algorithm for land (SEBAL), 1. Formulation, J. Hydrol., 212-213, 198-212, 1998.

Beziat, P., Ceschia, E., and Dedieu, G.: Carbon balance of a three crop succession over two cropland sites in South West France, Agr. Forest Meteorol., 149, 1628-1645, 2009.

Bird, R. E. and Hulstrom, R. L.: Review, evaluation, and improvement of direct irradiance models, J. Sol. Energy Eng. Trans.ASME, 103, 182-192, 1981.

Boulet, G., Chehbouni, A., Gentine, P., Duchemin, B., Ezzahar, J., and Hadria, R.: Monitoring water stress using time series of observed to unstressed surface temperature difference, Agr. Forest Meteorol., 146, 159-172, 2007.
Ceschia, E., Beziat, P., Dejoux, J. F., Aubinet, M., Bernhofer, C., Bodson, B., Buchmann, N., Carrara, A., Cellier, P., Di Tommasi, P., Elbers, J. A., Eugster, W., Grunwald, T., Jacobs, C. M. J., Jans, W. W. P., Jones, M., Kutsch, W., Lanigan, G., Magliulo, E., Marloie, O., Moors, E. J., Moureaux, C., Olioso, A., Osborne, B., Sanz, M. J., Saunders, M., Smith, P., Soegaard, H., and Wattenbach, M.: Management effects on net ecosystem carbon and GHG budgets at European crop sites, Agr. Ecosyst. Environ., 139, 363-383, 2010.

Chavez, J. L., Neale, C. M. U., Prueger, J. H., and Kustas, W. P.: Daily evapotranspiration estimates from extrapolating instantaneous airborne remote sensing ET values, Irrig. Sci., 27, 67-81, 2008.

Cleugh, H. A., Leuning, R., Mu, Q. Z., and Running, S. W.: Regional evaporation estimates from flux tower and MODIS satellite data, Remote Sens. Environ., 106, 285-304, 2007.

Colaizzi, P. D., Evett, S. R., Howell, T. A., and Tolk, J. A.: Comparison of five models to scale daily evapotranspiration from onetime-of-day measurements. T. ASABE, 49, 1409-1417, 2006.

Courault, D., Seguin, B., and Olioso, A.: Review on estimation of evapotranspiration from remote sensing data: From empirical to numerical modeling approaches, Irrig. Drain. Syst., 19, 223-249, 2005.

Crago, R. and Brutsaert, W.: Daytime evaporation and the selfpreservation of the evaporative fraction and the Bowen ratio, J. Hydrol., 178, 241-255, 1996.

Demarez, V., Duthoit, S., Weiss, M., Baret, F., and Dedieu, G.: Estimation of leaf area index (LAI) of wheat, maize and sunflower crops using digital hemispherical photographs, Agr. Forest Meteorol., 148, 644-655, 2008.

Dolman, A., Noilhan, J., Durand, P., Sarrat, C., Brut, A., Piquet, B., Butet, A., Jarosz, N., Brunet, Y., Loustau, D., Lamaud, E., Tolk, L., Ronda, R., Miglietta, F., Gioli, B., Magliulo, V., Esposito, M., Gerbig, C., Korner, S., Glademard, R., Ramonet, M., Ciais, P., Neininger, B., Hutjes, R., Elbers, J., Macatangay, R., Schrems, O., Perez-Landa, G., Sanz, M., Scholz, Y., Facon, G., Ceschia, E., and Beziat, P.: The CarboEurope regional experiment strategy, B. Am. Meteorol. Soc., 87, 1367-1379, 2006.

Gentine, P., Entekhabi, D., Chehbouni, A., Boulet, G., and Duchemin, B.: Analysis of evaporative fraction diurnal behaviour, Agr. Forest Meteorol., 143, 13-29, 2007.

Gentine, P., Entekhabi, D., and Polcher, J.: The diurnal behavior of evaporative fraction in the soil-vegetation-atmospheric boundary layer continuum, J. Hydrometeorol., 12, 1530-1546, 2011.

Hain, C. R., Mecikalski, J. R., and Anderson, M. C.: Retrieval of an Available Water-Based Soil Moisture Proxy from Thermal Infrared Remote Sensing, Part I: Methodology and Validation, J. Hydrometeorol., 10, 665-683, 2009.

Hoedjes, J. C. B., Chehbouni, A., Jacob, F., Ezzahar, J., and Boulet, G.: Deriving daily evapotranspiration from remotely sensed instantaneous evaporative fraction over olive orchard in semi-arid Morocco, J. Hydrol., 354, 53-64, 2008.

Jackson, R. D., Hatfield, J. L., Reginato, R. J., Idso, S. B., and Pinter, P. J.: Estimation of daily evapo-transpiration from one timeof-day measurements, Agr. Water Manage., 7, 351-362, 1983.

Kalma, J. D., McVicar, T. R., and McCabe, M. F.: Estimating Land Surface Evaporation: A Review of Methods Using Remotely Sensed Surface Temperature Data, Surv. Geophys., 29, 421-469, 2008. 
Kpemlie, E.: Assimilation variationnelle de données de télédétection dans des modèles de fonctionnements des couverts végétaux et du paysage agricole, Thèse de doctorat, Université d'Avignon et des Pays de Vaucluse, Avignon (FRA), 350 pp., 2009.

Kustas, W. and Anderson, M.: Advances in thermal infrared remote sensing for land surface modeling, Agr. Forest Meteorol., 149, 2071-2081, 2009.

Kutsch, W. L., Aubinet, M., Buchmann, N., Smith, P., Osborne, B., Eugster, W., Wattenbach, M., Schrumpf, M., Schulze, E. D., Tomelleri, E., Ceschia, E., Bernhofer, C., Béziat, P., Carrara, A., Di Tommasi, P., Grünwald, T., Jones, M., Magliulo, V., Marloie, O., Moureaux, C., Olioso, A., Sanz, M. J., Saunders, M., Søgaard, H., and Ziegler, W.: The net biome production of full crop rotations in Europe, Agr. Ecosyst. Environ., 139, 336-345, 2010.

Lagouarde, J.-P., Bach, M., Sobrino, J. A., Boulet, G., Briottet, X., Cherchali, S., Coudert, B., Dadou, I., Dedieu, G., Gamet, Ph., Hagolle, O., Jacob, F., Nerry, F., Olioso, A., Ottlé, C., Roujean, J.-L., and Fargant, G.: The MISTIGRI Thermal Infrared project: scientific objectives and mission specifications, Int. J. Remote Sens., in press., 2012.

Lhommel, J.-P.: Towards a rational definition of potential evaporation, Hydrol. Earth Syst. Sci., 1, 257-264, doi:10.5194/hess-1257-1997, 1997.

Lhomme, J.-P. and Elguero, E.: Examination of evaporative fraction diurnal behaviour using a soil-vegetation model coupled with a mixed-layer model, Hydrol. Earth Syst. Sci., 3, 259-270, doi:10.5194/hess-3-259-1999, 1999.
Meeus, J.: Astronomical Algorithms, Willmann-Bell, Inc., Richmond, 477 pp., 1999.

Nichols, W. E. and Cuenca, R. H.: Evaluation of the evaporative fraction for parameterization of the surface, energy-balance, Water Resour. Res., 29, 3681-3690, 1993.

PNUE PAM Plan Bleu : L'eau des Méditerranéens: situation et perspectives, 158, PNUE/PAM, Athènes, 2004.

Santanello, J. A. and Friedl, M. A.: Diurnal covariation in soil heat flux and net radiation, J. Appl. Meteorol., 42, 851-862, 2003.

Shuttleworth, W. J., Gurney, R. J., Hsu, A. Y., and Ormsby, J. P.: FIFE: the variation in energy partition at surface flux sites, IAHS Publ., 186, 67-74, 1989.

Sobrino, J. A., Gómez, M., Jiménez-Muñoz, J. C., and Olioso, A.: Application of a Simple Algorithm to Estimate Daily Evapotranspiration from NOAA-AVHRR Images for the Iberian Peninsula, Remote Sens. Environ., 110, 139-148. 2007.

Su, Z.: The Surface Energy Balance System (SEBS) for estimation of turbulent heat fluxes, Hydrol. Earth Syst. Sci., 6, 85-100, doi:10.5194/hess-6-85-2002, 2002.

Van Niel, T. G., McVicar, T. R., Roderick, M. L., van Dijk, A. I. J. M., Renzullo, L. J., and Van Gorsel, E.: Correcting for systematic error in satellite-derived latent heat flux due to assumptions in temporal scaling: Assessment from flux tower observations, J. Hydrol., 409, 140-148, 2011.

Venturini, V., Islam, S., and Rodriguez, L.: Estimation of evaporative fraction and evapotranspiration from MODIS products using a complementary based model, Remote Sens. Environ., 112, 132-141, 2008. 